\title{
Nursing Students' Perception and Attitude towards Objective Structured Clinical Examination in Oman
}

Shaikha Alamri, "Iman Al Hashmi, Kholah Shruba, Suad Jamaan, Zaina Alrahbi, Thuraiya Al Kaabi

\begin{abstract}
Objectives: This study aimed to explore undergraduate nursing students' perception and attitude towards the Objective Structured Clinical Examination (OSCE). Methods: This cross-sectional descriptive study was conducted between April-May 2020 among undergraduate nursing students at the College of Nursing at Sultan Qaboos University, Muscat, Oman. Two self-administered questionnaires were utilised to obtain data on students' perception and attitude towards OSCE. Students' feedback on OSCE was collected using open-ended questions about OSCE strengths, weaknesses and recommendations for improvement. Survey responses were based on a fivepoint ordinal scale, ranging from strongly disagree to strongly agree. Students' feedback on OSCE was analysed as descriptive data by identifying the common themes and categorising them in groups. Results: A total of 160 students completed the study questionnaires. Most did not find the atmosphere of OSCE to be pleasant (66.3\%) and preferred more modes of practical examination (40.6\%). Moreover, $64.4 \%$ believed the time limitation to be inadequate. The data depict that $33.1 \%$ of the examinees deemed the OSCE more stressful than the full practical examination. In addition, a few students confirmed that the OSCE improved their communication skills and confidence in nursing skills. Conclusion: The findings of this study appear alarming in regard to students' perception regarding the overall process and validity of OSCE as an assessment method. Nursing educators must consider further evaluation and improvement of the OSCE in order to improve students' acceptance and appreciation of OSCE as an important form of clinical learning and assessment.
\end{abstract}

Keywords: Clinical Competence; Nursing Education; Baccalaureate; Evaluation; Attitude; Nursing Students; Practical Nursing; Oman.

\footnotetext{
Advances IN KNOWLEDGE

The study indicates that further improvement of the Objective Structured Clinical Examination (OSCE) is necessary to ensure better assessment of student's clinical skills and knowledge.

Adequate preparation of students prior to the OSCE, determination of the appropriate time-frame for each station and encouragement of examiner's positive attitudes during the exam are recommended strategies for reducing OSCE-related stress and improving students' overall performance.

Technical preparation, adequate orientation of examinee and examiners and redesigning of the skill laboratories for enhanced legitimacy are required for more efficient and effective conduction of the OSCE.

\section{Application to Patient Care}

The Objective Structured Clinical Exam is an effective assessment strategy for measuring the clinical competence of nursing students to ensure patient safety and quality of care.
}

\section{$\mathrm{T}$} he objective Structured Clinical Examination (OSCE) is a universal format used by healthcare professionals to measure students' clinical competence. ${ }^{1}$ In nursing programmes, clinical education forms the core of a nurse's professional practice. Therefore, assessing nursing students' clinical competence is crucial to their education. ${ }^{2}$ The OSCE has gained acceptance since its development in the 1970s as a method to evaluate the clinical performance of nursing students. ${ }^{3}$ It uses standardised scenarios that mimic real-life clinical situations and is administered in a highly controlled environment. ${ }^{4}$ Unlike traditional clinical exams, which have been criticised for lacking objectivity and uniformity, ${ }^{5}$ the OSCE is one of the most reliable assessment tools; it enhances students' learning, allowing students to demonstrate the full extent of their knowledge and skills, all the while providing a more objective method of assessment., ${ }^{5,6}$ Additionally, the simulation of patients in OSCEs provides a safe environment for students to practice a wide range of practical skills without feeling discomposed about causing harm to the patient. It further creates a culture relatively similar to the hospital environment. ${ }^{7}$ OSCE helps in enhancing the safety and quality of nursing care and ultimately prepares students for their future professional role. Besides the summative assessment, OSCE can also be used as a formative assessment through which the 
nursing educator provides feedback to students as part of the teaching process. ${ }^{1}$

While the OSCE has been found to be an effective method in clinical education and assessment, ${ }^{2,4}$ it may also induce high levels of anxiety in students due to its interactive nature. ${ }^{8,9}$ Several studies have documented that nursing students found the OSCE to be quite stressful, such that they were unable to perform well compared to their relative performance in the actual clinical environment. This is due to the pressure of observation by examiners as well as the time limit allocated for each skill. ${ }^{9}$ Furthermore, several students perceive the OSCE as a noncomprehensive examination that does not reflect reality since simulated patients or mannequins are utilised instead of real patients. These responses might not be conclusive, yet it is imperative to look into the OSCE as an effective tool to support student learning needs. ${ }^{8,10}$

To the best of the authors' knowledge, the perception and attitude of Omani nursing students about the OSCE as an assessment approach has not been comprehensively documented. The published studies are limited as they either evaluate the impact of test anxiety on the students' academic performance or compare their self-assessment to the examiners' assessment in the OSCE. ${ }^{11,12}$ None of the abovementioned studies have addressed the perception of Omani nursing students regarding the OSCE. This study aimed to fill this gap in the literature and lay a foundation for succeeding studies that seek to understand Omani nursing students' perceptions of the OSCE. It seeks to do this by investigating the perception and the attitude of Omani nursing students towards the OSCE.

\section{Methods}

This cross-sectional descriptive study was conducted at the College of Nursing (CON), Sultan Qaboos University (SQU), Muscat, Oman from April-May 2020. The $\mathrm{CON}$ is one of the leading nursing colleges for both baccalaureate and master degrees across the country. It is internationally recognised and accredited by the Accreditation Commission for Education in Nursing. Students enrolled at SQU predominately comprise Omani citizens from various regions; thus, it is the ideal setting for the study as the students represent the Omani nursing student population.

The OSCE is a scenario-based assessment method in which the student is required to demonstrate safe and high-quality skills related to nursing care in a simulated environment on standardised patients or mannequins. In the OSCE, students' clinical competence is assessed at a series of stations, which are developed according to the course objectives.

At SQU, the OSCE is considered a standard method of assessment for undergraduate nursing students and is implemented across all clinical courses. The entire nursing faculty in the CON are well prepared to conduct OSCE and receive frequent training in OSCE development. The CON's laboratories maintain state-of-the-art equipment that can easily replicate the environment of healthcare facilities. Standardised patients and low-fidelity and high-fidelity mannequins are utilised in the OSCE stations as deemed convenient by the clinical course coordinator. The OSCE scenarios are developed by $\mathrm{PhD}$ nursing faculty by replicating real clinical cases. The examination may include two to three manned stations, each requiring about 15-20 minutes depending on the skill being tested. At least two examiners are responsible for assessing students' performance on the required clinical competence and rate them on a standardised assessment tool with a predetermined safety criterion. Students rotate through the OSCE stations in order to complete the exam. This means that all students complete the same stations, and hence, are assessed using the same assessment tool.

The sample for this study comprised active Omani undergraduate nursing students attending the $\mathrm{CON}$ at SQU during the study timeframe. The sample was required to be able to speak, read and write in Arabic, with a previous experience with OSCE as an assessment method. Undergraduate nursing students with known anxiety disorders or those without previous experience with the OSCE were excluded from the study. During the study timeframe, 250 nursing students were identified with a previous experience of OSCE and met the inclusion criteria. The sample size was calculated using the Yamane formula. Considering that the accessible population was equal to 250 subjects, the formula indicated that a sample size of 109 participants at a confidence level of $95 \%$ and an error of $5 \%$ was adequate to achieve a minimum power of $80 \%$. Incorporating a $10 \%$ attrition rate, the final required sample size was set at 119 subjects. Convenient sampling was used to recruit the required study sample.

Four instruments were forwarded to the potential participants, including the demographic information sheet, the nursing students' perception of the OSCE tool, the students' attitude towards the OSCE and the students' feedback on the OSCE. All the instruments provided to the participants were in Arabic. Approval to use these instruments was obtained from the tools' developer prior to use. 
The demographic information sheet was developed by the study investigators and included data on participants' gender, academic year, OSCE course name and type of study track. The perception of OSCE tool was used to assess the nursing students' perception before, during and after OSCE. ${ }^{13}$ This 11 -item, selfadministered structured questionnaire was scored on a five-point ordinal scale ranging from 'strongly disagree' to 'strongly agree.' Responses were grouped as positive responses (including agree and strongly agree) or negative responses (including disagree and strongly disagree), with positive responses suggestive of students' good perception of the OSCE. The internal reliability of the original tool was deemed to be good (Cronbach's alpha value: 0.9)..$^{13}$

The 12-item Attitude towards OSCE scale was used to measure the attitude of nursing students towards OSCE. ${ }^{14}$ Students' responses were scored on a five-point ordinal scale ranging from 'strongly disagree' to 'strongly agree', with positive scores indicating students' good attitude towards OSCE. The internal reliability of the original tool was established to be good. ${ }^{14}$ Students' feedback regarding the OSCE was assessed through three open-ended questions concerning the strengths and the weaknesses of the examination from the students' perspective and their recommendations to improve OSCE. ${ }^{14}$

The data were analysed using the Statistical Package for Social Sciences (SPSS) software, Version 24.0 (IBM Corporation, Armonk, New York, USA) and double-checked for accuracy. The results were checked for outliers or missing data to determine the need for transformation or use of non-parametric methods. Descriptive statistics and graphical summaries were run for all the key outcomes. Categorical variables were presented as frequencies and percentages. An ANOVA test was employed to test the difference between students' academic year and their perception and attitude towards the OSCE. Students' feedback on the OSCE was analysed as descriptive data by identifying similar themes and subsequently categorising them into groups.

Prior to the beginning of the study procedures, ethical approval was obtained from the Scientific Ethics Committee at the CON (CON/GP/2020/01). The participant recruitment process was coordinated with the help of the assistant dean of undergraduate study as well as the course coordinators of the clinical nursing courses, who had been informed of the study purpose and eligibility criteria. A list of all clinical nursing courses that had used OSCE in the previous semester was generated along with the students' email list. The study investigators manually checked students' emails against courses to prevent duplication of participants. All the students in the list were invited to participate in the study via email, which included the study information sheet (e.g. purpose, study title, researchers, eligibility criteria, participants' role and study expectations) and an electronic link to the study questionnaires and the consent form. To prevent measurement-related errors, the investigators standardised the procedure by providing uniform information and instruction to all potential participants.

\section{Results}

A total of 160 nursing undergraduate students completed the study questionnaire with a $0 \%$ attrition rate. Of these, 127 (79.4\%) were female and 31(19.4\%) were male. Most of the students were in their third ( $\mathrm{n}$ $=42 ; 26.3 \%)$ and fourth year $(n=57 ; 35.6 \%)$ [Table 1 ].

The extent and the quality of information with respect to OSCE was determined. Most of the students rated the OSCE negatively, as they disagreed with the view that OSCE equipment and scenarios are realistic, relevant and logistic $(\mathrm{n}=83 ; 51.9 \%)$. They also disagreed with the notion that the time allowed to read OSCE instructions ( $\mathrm{n}=96 ; 60 \%$ ) and the time allocated to complete the skill ( $\mathrm{n}=103 ; 64.4 \%)$ was sufficient. More than the half of the students $(n=94 ; 58.8 \%)$ perceived

Table 1: Sample demographic and academic characteristics $(\mathrm{N}=160)$

$\begin{array}{lc}\text { Characteristic } & \mathbf{n}(\%) \\ \text { Gender } & \\ \text { Female } & 31(19.4) \\ \text { Male } & 2(1.3) \\ \text { Missing } & \\ \text { Academic Year } & 8(5) \\ \text { First Year } & 8(5) \\ \text { Second Year } & 42(26.3) \\ \text { Third Year } & 57(35.6) \\ \text { Fourth Year } & 53(33.1) \\ \text { Missing } & \\ \text { Academic Track } & 131(81.9) \\ \text { Regular Track } & 28(17.5) \\ \text { Bridging } & 1(0.6) \\ \text { Missing } & 153(95.6) \\ \text { Previous OSCE experience } & 1(0.6) \\ \text { Yes } & \end{array}$


Table 2: Nursing students' perception towards Objective Structured Clinical Examination $(\mathrm{N}=160)$

\begin{tabular}{|c|c|c|c|}
\hline \multirow[t]{2}{*}{ Item } & \multicolumn{3}{|c|}{ n (\%) } \\
\hline & Positive & Negative & Missing \\
\hline $\begin{array}{l}\text { OSCE atmosphere } \\
\text { is good }\end{array}$ & $51(31.9)$ & $106(66.3)$ & $\begin{array}{c}3 \\
(1.9)\end{array}$ \\
\hline $\begin{array}{l}\text { Extent and quality of } \\
\text { information received } \\
\text { about OSCE }\end{array}$ & $70(43.8)$ & $87(54.4)$ & $\begin{array}{c}3 \\
(1.9)\end{array}$ \\
\hline $\begin{array}{l}\text { Enough time allowed } \\
\text { for reading the } \\
\text { instruction }\end{array}$ & $62(38.8)$ & $96(60)$ & $\begin{array}{c}2 \\
(1.3)\end{array}$ \\
\hline $\begin{array}{l}\text { Time allotted for the } \\
\text { completion of the } \\
\text { procedure is enough }\end{array}$ & $54(33.8)$ & $103(64.4)$ & $\begin{array}{c}3 \\
(1.9)\end{array}$ \\
\hline $\begin{array}{l}\text { Equipment and } \\
\text { scenarios are realistic, } \\
\text { relevant and logistic }\end{array}$ & 77 (48.1) & 83 (51.9) & $\begin{array}{c}0 \\
(0.0)\end{array}$ \\
\hline $\begin{array}{l}\text { Examiners are } \\
\text { courteous, friendly } \\
\text { and cooperative }\end{array}$ & $62(38.8)$ & $94(58.8)$ & $\begin{array}{c}4 \\
(2.5)\end{array}$ \\
\hline $\begin{array}{l}\text { Procedures given in } \\
\text { OSCE are applicable } \\
\text { during clinical } \\
\text { posting }\end{array}$ & $84(52.5)$ & $76(47.5)$ & $\begin{array}{c}0 \\
(0.0)\end{array}$ \\
\hline $\begin{array}{l}\text { Confidence to } \\
\text { conduct a similar } \\
\text { procedure on a real } \\
\text { patient is high }\end{array}$ & $78(48.8)$ & $80(50)$ & $\begin{array}{c}2 \\
(1.3)\end{array}$ \\
\hline $\begin{array}{l}\text { Student perceptions } \\
\text { on OSCE results }\end{array}$ & $78(48.8)$ & $80(50)$ & $\begin{array}{c}2 \\
(1.3)\end{array}$ \\
\hline $\begin{array}{l}\text { Continue the way } \\
\text { OSCE was conducted } \\
\text { as a practical } \\
\text { examination in the } \\
\text { future }\end{array}$ & $64(40)$ & $91(56.9)$ & $\begin{array}{c}5 \\
(3.1)\end{array}$ \\
\hline $\begin{array}{l}\text { Helped students } \\
\text { to identify their } \\
\text { deficiencies in clinical } \\
\text { skills }\end{array}$ & $70(43.8)$ & $90(56.3)$ & $\begin{array}{c}0 \\
(0.0)\end{array}$ \\
\hline
\end{tabular}

OSCE = Objective Structured Clinical Examination

OSCE examiners as being uncorteous, unfriendly and non-cooperative. However, half the students ( $\mathrm{n}=84$; $52.5 \%)$ declared a positive view that the procedures given in OSCE were applicable during clinical posting, and $78(48.8 \%)$ possessed a high level of confidence to demonstrate the same procedure on a real patient. Only 70 (43.8\%) students believed that OSCE helped them identify their deficiencies in clinical skills, while the remaining 90 (56.3\%) disagreed with this statement. Furthermore, 91 (56.9\%) did not support the statement 'to continue the way the OSCE was conducted as a practical examination in the future' [Table 2].

Regarding students' attitude towards the OSCE, 57 (35.6\%) believed that the OSCE encourages students to be more attentive in practical classes,
Table 3: Students' attitude towards Objective Structured Clinical Examination $(\mathrm{N}=160)$

\begin{tabular}{|c|c|c|c|c|}
\hline \multirow[t]{2}{*}{ Item } & \multicolumn{4}{|c|}{ n (\%) } \\
\hline & Positive & Negative & Neutral & Missing \\
\hline $\begin{array}{l}\text { OSCE } \\
\text { encourages } \\
\text { students } \\
\text { to be more } \\
\text { attentive } \\
\text { in practical } \\
\text { class. }\end{array}$ & $57(35.6)$ & $\begin{array}{c}60 \\
(37.5)\end{array}$ & $42(26.3)$ & $\begin{array}{c}1 \\
(0.6)\end{array}$ \\
\hline $\begin{array}{l}\text { There is } \\
\text { ample time } \\
\text { at all the } \\
\text { stations. }\end{array}$ & 47 (29.4) & $\begin{array}{c}73 \\
(45.6)\end{array}$ & $36(22.5)$ & $\begin{array}{c}4 \\
(2.5)\end{array}$ \\
\hline $\begin{array}{l}\text { OSCE tests } \\
\text { details of the } \\
\text { steps of a } \\
\text { procedure. }\end{array}$ & $62(38.8)$ & $\begin{array}{c}50 \\
(31.3)\end{array}$ & $47(29.4)$ & $\begin{array}{c}1 \\
(0.6)\end{array}$ \\
\hline $\begin{array}{l}\text { OSCE is } \\
\text { a more } \\
\text { challenging } \\
\text { form of } \\
\text { examin- } \\
\text { ation. }\end{array}$ & 57 (35.6) & $\begin{array}{c}33 \\
(20.6)\end{array}$ & $68(42.5)$ & $\begin{array}{c}2 \\
(1.3)\end{array}$ \\
\hline $\begin{array}{l}\text { OSCE tests } \\
\text { recall of } \\
\text { knowledge. }\end{array}$ & $58(36.3)$ & $\begin{array}{c}57 \\
(35.6)\end{array}$ & $46(28.1)$ & $\begin{array}{c}0 \\
(0.0)\end{array}$ \\
\hline $\begin{array}{l}\text { OSCE is } \\
\text { quite an easy } \\
\text { examin- } \\
\text { ation. }\end{array}$ & 51 (31.9) & $\begin{array}{c}58 \\
(36.3)\end{array}$ & $51(31.9)$ & $\begin{array}{c}0 \\
(0.0)\end{array}$ \\
\hline $\begin{array}{l}\text { Time is } \\
\text { sufficient at } \\
\text { procedural } \\
\text { stations. }\end{array}$ & $52(32.5)$ & $\begin{array}{c}66 \\
(41.3)\end{array}$ & $38(23.8)$ & $\begin{array}{c}4 \\
(2.5)\end{array}$ \\
\hline $\begin{array}{l}\text { OSCE } \\
\text { should be the } \\
\text { only mode } \\
\text { of practical } \\
\text { examin- } \\
\text { ation. }\end{array}$ & $62(38.8)$ & $\begin{array}{c}65 \\
(40.6)\end{array}$ & $\begin{array}{c}32 \\
(20.0)\end{array}$ & $1(0.6)$ \\
\hline $\begin{array}{l}\text { Cannot pass } \\
\text { in OSCE } \\
\text { without } \\
\text { attending } \\
\text { class } \\
\text { regularly. }\end{array}$ & $56(35.0)$ & $\begin{array}{c}59 \\
(36.9)\end{array}$ & $45(28.1)$ & $\begin{array}{c}0 \\
(0.0)\end{array}$ \\
\hline $\begin{array}{l}\text { OSCE } \\
\text { is more } \\
\text { stressful } \\
\text { than a full } \\
\text { practical } \\
\text { examin- } \\
\text { ation. }\end{array}$ & $53(33.1)$ & $\begin{array}{c}42 \\
(26.3)\end{array}$ & 63 (39.4) & $\begin{array}{c}3 \\
(1.3)\end{array}$ \\
\hline $\begin{array}{l}\text { Easier to } \\
\text { pass in } \\
\text { OSCE } \\
\text { than in full } \\
\text { practical } \\
\text { examin- } \\
\text { ations }\end{array}$ & $58(36.3)$ & $\begin{array}{c}61 \\
(38.1)\end{array}$ & $\begin{array}{c}40 \\
(25.0)\end{array}$ & $\begin{array}{c}1 \\
(0.6)\end{array}$ \\
\hline $\begin{array}{l}\text { Not much } \\
\text { difference } \\
\text { between } \\
\text { OSCE } \\
\text { and other } \\
\text { practical } \\
\text { examin- } \\
\text { ations. }\end{array}$ & $54(33.8)$ & $\begin{array}{c}68 \\
(42.5)\end{array}$ & 37 (23.1) & $1(0.6)$ \\
\hline
\end{tabular}

OSCE = Objective Structured Clinical Examination. 
Table 4: Effect of students' academic year on students' perception and attitude towards Objective Structured Clinical Examination

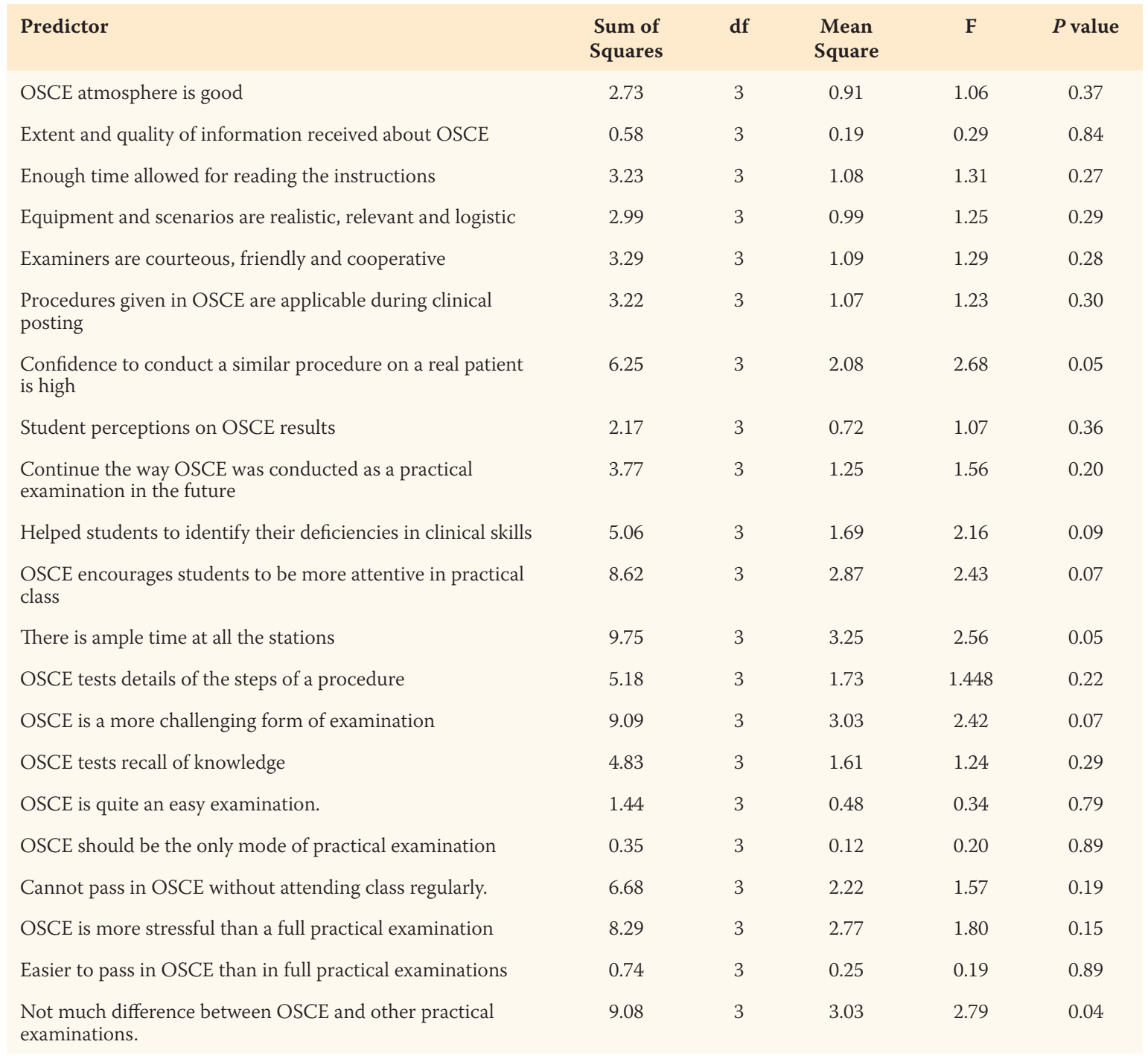

OSCE = Objective Structured Clinical Examination

Table 5: OSCE-related strengths as percieved by nursing students attending the College of Nursing at Sultan Qaboos University, Muscat, Oman $(\mathrm{N}=160)$

$\begin{array}{lc}\begin{array}{l}\text { Strength } \\ \text { OSCE improves students' skills and } \\ \text { communication }\end{array} & \text { n (\%) } \\ \begin{array}{l}\text { OSCE increases students' confidence level } \\ \text { OSCE helps students to learn time } \\ \text { management }\end{array} & 7(11.0) \\ \begin{array}{l}\text { OSCE gives students the chance to work in a } \\ \text { hospital-like environment }\end{array} & 3(5.0) \\ \begin{array}{l}\text { OSCE improves students' critical thinking } \\ \text { OSCE = Objective Structured Clinical Examination. }\end{array} & 3(5.0)\end{array}$

while the remaining either disagreed $(n=60 ; 37.5 \%)$ or remained neutral $(\mathrm{n}=42 ; 26.3 \%)$ regarding this notion. The majority $(\mathrm{n}=57 ; 35.6 \%)$ of the responses indicated positively that the OSCE is a more challenging form of examination and 53 (33.1\%) students believed the
Table 6: OSCE-related weaknesses as percieved by nursing students attending the College of Nursing at Sultan Qaboos University, Muscat, Oman ( $\mathrm{N}=160)$

\begin{tabular}{lc|}
\hline Weakness & $\begin{array}{c}\text { Total Sample } \\
\text { N (\%) }\end{array}$ \\
\hline OSCE is a stressful examination & $22(35.0)$ \\
There is time limit to perform procedures & $15(24.0)$ \\
Unfriendly examiners & $5(8.0)$ \\
Nature of the examination is not good & $3(5.0)$
\end{tabular}

OSCE to be more stressful than clinical examination. Furthermore, 54 (33.8\%) students argued that there was not much difference between the OSCE and other clinical examinations and 56 (35.0\%) declared that they could not pass the OSCE without attending their classes regularly. Moreover, the majority of students ( $\mathrm{n}$ $=65 ; 40.6 \%$ ) disagreed that the OSCE should be the only mode of practical examination [Table 3]. 
The analysis of variance indicated that the effect of the students' academic year was significant on their perception of 'not much difference between OSCE and other practical examinations' $(\mathrm{F}[3,155]=2.79, P$ $=0.04)$ and 'there is ample time at all the stations' ( $\mathrm{F}$ $[3,155]=2.56, P=0.05)$ [Table 4].

The OSCE's strengths frequently reported by students are that it improves students' skills and communication ( $\mathrm{n}=13 ; 21 \%)$ and increases students' confidence level ( $\mathrm{n}=7 ; 11 \%$ ) [Table 5].

The top OSCE-related weaknesses declared by the participants include the OSCE being a stressful examination $(\mathrm{n}=22 ; 35 \%)$ and the time limit $(\mathrm{n}=15$; $24 \%)$. Other reported weaknesses include unfriendly examiners $(n=5 ; 8 \%)$ [Table 6].

The recommendations provided by the students to improve their experiences during the OSCE included providing at least 30 minutes of time to perform the skill ( $\mathrm{n}=26 ; 42 \%)$ as well as enough lab practice prior to the examination $(\mathrm{n}=10 ; 16 \%)$.

\section{Discussion}

OSCE is considered the gold standard for assessing the clinical proficiency of health professionals in various health-related institutions worldwide. ${ }^{15,16}$ In nursing programmes, clinical assessment competence is one of the core components that the students must master to be able to provide safe and quality nursing care. ${ }^{17}$ The sample of the current study revealed unfavourable and negative responses for the OSCE in the context of practical examination, which varies from other evidence that reported overall favourable perception and attitude towards the OSCE. ${ }^{18-20}$ Students' view of the OSCE might have been influenced by stress and lack of confidence and preparation associated with this assessment method. In this study, more than onethird of the participants declared the OSCE to be a stress-inducing and difficult examination. This finding is consistent with observations from other studies; however, it contradicts the study conducted by Shitu and Girma (2018), ${ }^{9,21}$

More than half the students indicated that they had not received adequate orientation to the OSCE, believing OSCE's simulations to be unrealistic, irrelevant and illogical. This finding is consistent with other similar studies. ${ }^{22}$ Lack of awareness of, preparation for and orientation to the exam format may negatively impact students' stress level and performance in the OSCE. ${ }^{23}$ Therefore, it is recommended to brief students and provide them with adequate information regarding the nature, format, objectives and content of each station to decrease their stress level during the examination, thereby improving their performance. ${ }^{18}$ Additionally, $60 \%$ of the study participants believed that the time allocated to read OSCE instructions was insufficient. Similarly, $64.4 \%$ of them stated that the time allocated to complete the procedure was inadequate and suggested increasing the time up to thirty minutes. These findings are consistent with other studies, in which more than half the study participants mentioned the need for more time to complete each station in the OSCE..$^{15,18}$ Unrealistic time limits for each station may be one of the reasons for students' anxiety. ${ }^{24}$ Usually, during the development stage of the OSCE, nursing educators estimate the time allocated to each station considering several factors, such as learning outcomes, students' level, objectives and the skill being assessed. This study suggests that the instructors perform OSCE trials to determine the time required for each station. This could decrease students' stress and improve their scores for the OSCE..$^{25}$ Additionally, training the students in time management prior to the adminsteration of the OSCE is important.

The results of this study indicate that more than half the students found the examiners at manned stations to be uncourteous, unfriendly and noncooperative. Concerns regarding unsympathetic characteristics of the examiners have also been reported in previous studies. ${ }^{21}$ This provides another potential explanation for the students' stress perceived during the OSCE. This finding has an important implication for OSCE developers who need to orient and prepare examiners adequately for the examination to positively influence students' performance.

A high percentage (56.9\%) of the study participants suggested the OSCE be reconstructed for practical examinations in the future. Moreover, almost a similar percentage of the students (40.6\%) implied that the OSCE should not be the only method for practical examination. This contradicts Chongloi et al., who found that their study participants preferred the OSCE to be the only method for practical examination as they believed it requires less preparation and efforts and values high scores. ${ }^{18}$ In the current study, almost half the students indicated that the OSCE did not help them identify their deficiencies in clinical skills or improve their confidence level for similar procedures on real patients. In contrast, Aung et al. observed that the OSCE provided the majority of the participants the opportunity to practice rare or advanced nursing procedures. $^{26}$ Consequently, the OSCE practice improved students' confidence level to demonstrate similar procedures on a real patient. In the current study, the students suggested having adequate practice 
prior to the OSCE. This was possibly due to the students' inexperience with this method of evaluation. Practice trials may help in the improvement of students' confidence level to perform clinical skills and their acceptance and appreciation of OSCE as a significant way of clinical learning.

Furthermore, students in this study recommended the organisation of all OSCE stations in a single area. This finding exemplifies the importance of focusing not only on the OSCE process and preparation, but also on the environment and setting of the exam. The skill laboratories in the facility lack space and are not well-designed to conduct OSCE. Therefore, their structure must be reconsidered to conduct the OSCE more effectively.

To the best of the authors' knowledge, this is the first study of its kind in Oman among nursing students. It provides an insight regarding OSCE from the perspective of Omani nursing students. The major strengths of this study include the study design, adequate sample size and the use of validated questionnaires. Altogether, these aspects provide greater confidence regarding the study results. In addition to the above-mentioned strengths, a few limitations must be acknowledged while interpreting the results of this study. First, this study was conducted after one semester had passed following the OSCE, as the teaching in the institution was suspended due to the COVID-19 pandemic. Therefore, students' recollection of the OSCE might have been impacted during that time period. Second, this study cannot be generalised among nursing students as it was conducted in a single institution and on a relatively smaller sample of students by employing convenience sampling.

\section{Conclusion}

The authors' findings of nursing students' perception of the OSCE were consistent with a few previous studies. The majority of the participants provided unfavourable and negative responses for OSCE, including stressful examination, lack of confidence to perform, unrealistic timing to complete tasks, unfriendly examiners and poor organisation of OSCE stations. Therefore, providing students with practice trials before the OSCE, determining the appropriate time frame for each station, training the students in time management and encouraging positive examiner attitudes during the exam are recommended for reducing exam-related stress and improving students' performance. In addition, technical preparation and orientation of students as well as examiners to the exam process may aid in promoting its efficacy. Redesigning the skill laboratories for enhanced legitimacy would also allow for more efficient and effective conducting of the OSCE.

\section{AUTHORS' CONTRIBUTION}

SA, KS, SJ, ZA and TAK: conceived the project, collected the data and drafted the manuscript. IAH is the project lead, made conceptual contributions to the study design, analysed and intrepreted the statistical data and critically read the manuscript. All authors approved the final version of the manuscript.

\section{CONFLICT OF INTEREST}

The authors declare no conflicts of interest.

\section{FUNDING}

No funding was received for this study.

\section{References}

1. Elbilgahy AA, Eltaib FA, Mohamed RK. Implementation of objective structured clinical examination (OSCE): Perceiving nursing students and teachers attitude \& satisfaction. Am J Nurs 2020; 8:220-6. https://doi.org/10.12691/ajnr-8-2-11.

2. Smrekar M, Ledinski Fičko S, Hošnjak AM, Ilić B. Use of the objective structured clinical examination in undergraduate nursing education. Croatian Nurs J 2017; 1:91-102. https://doi. org $/ 10.24141 / 2 / 1 / 1 / 8$.

3. Miller GE. The assessment of clinical skills competence performance. Acad Med 1990; 65:S63-7. https://doi.org/10.1097/000 01888-199009000-00045.

4. Aronowitz T, Aronowitz S, Mardin-Small J, Kim B. Using objective structured clinical examination (OSCE) as education in advanced practice registered nursing education. J Prof Nurs 2017; 33:119-25. https://doi.org/10.1016/j.profnurs.2016.06.003.

5. Frantz JM, Rowe M, Hess DA, Rhoda AJ, Sauls BL, Wegner I. Student and staff perceptions and experiences of the introduction of objective structured practical examinations: A pilot study. Afr J Health Prof Educ 2013; 5:72-4. https://doi.org/10.7196/ AJHPE.218.

6. Kowlowitz V, Hoole AJ, Sloane PD. Implementing the objective structured clinical examination in a traditional medical school: Academic medicine. J Assoc Am Med Coll 1991; 66:345-7. https://doi.org/10.1097/00001888-199106000-00008.

7. Zayyan M. Objective structured clinical examination: The assessment of choice. Oman Med J 2011; 26:219. https://doi. org/10.5001/omj.2011.55

8. Al-Ghareeb A, McKenna L, Cooper S. The influence of anxiety on student nurse performance in a simulated clinical setting: A mixed methods design. Int J Nurs Stud 2019; 98:57-66. https:// doi.org/10.1016/j.ijnurstu.2019.06.006

9. Nasir AA, Yusuf AS, Abdur-Rahman LO, Babalola OM, Adeyeye AA, Popoola AA, et al. Medical students' perception of objective structured clinical examination: A feedback for process improvement. Jo Surg Educ 2014; 71:701-6. https://doi.org/10.1016/j. jsurg.2014.02.010.

10. Robinson P, Morton L, Haran H, Manton R. Mock OSCEs improve medical students' confidence and reduce anxiety related to summative examinations. Educ Med J 2017; 9:41-5. https://doi.org/10.21315/eimj2017.9.2.4. 
11. Qutishat MG, Leocadio M, Cayaban A. Extent of test anxiety among nursing students in Oman and impact on academic performance. J Health Sci Nurs 2018; 3:11-25.

12. Jahan F, Shaikh N, Norrish M, Siddqi N, Qasim R. Comparison of student's self-assessment to examiners assessment in a formative observed structured clinical examination: A pilot study. JPMI 2012; 27: 94-9.

13. Small LF, Pretorius L, Walters A, Ackerman M, Tshifugula P. Students' perceptions regarding the objective, structured, clinical evaluation as an assessment approach. Health SA 2013; 18:629-636. https://doi.org/10.4102/hsag.v18i1.629.

14. Malik SL, Manchanda SK, Deepak KK, Sunderam KR. The attitudes of medical students to the objective structured practical examination. Med Educ 1988; 22:40-6. https://doi.org/10.11 11/j.1365-2923.1988.tb00407.x.

15. Al-Zeftawy AM, Khaton SE. Student evaluation of an OSCE in community health nursing clinical course at faculty of nursing. Tanta University. IOSR J Nurs Health Sci 2016; 5:68-76. https:// doi.org/10.9790/1959-0504036876.

16. Al Nazzawi AA. Dental students' perception of the objective structured clinical examination (OSCE): The Taibah University experience, Almadinah Almunawwarah, KSA. J Taibah Univ Med Sci2018;13:64-9.https://doi.org/10.1016/j.jtumed.2017.09.002.

17. Association of Colleges of Nursing. The essentials of baccalaureate education for professional nursing practice. From: http://www.aacnnursing.org/Nursing-Education-Programs/ Baccalaureate-Education Accessed: Apr 2021.

18. Chongloi N, Thomas P, Ara M, Deepak KK. Attitudes of undergraduate nursing students toward objective structure practical examination: An exploratory study. Int J Nurs Sci 2017; 4:68-72. https://doi.org/10.1016/j.ijnss.2016.12.003.
19. Furlong E, Fox P, Lavin M, Collins R. Oncology nursing students' views of a modified OSCE. Eur J Oncol Nurs 2005; 9:351-9. https://doi.org/10.1016/j.ejon.2005.03.001.

20. Saeed A, Al Suwayh WM, Alomri AS. Students' perceptions and attitudes towards objective structured clinical examination (OSCE) in the College of Medicine, KSAU-HS, King Fahad Medical City, Riyadh, Saudi Arabia. J Med Sci Clin Res 2016; 4:9741-7. https://doi.org/10.18535/jmscr/v4i3.29.

21. Shitu B, Girma T. Objective structured clinical examination (OSCE): Examinee's perception at department of pediatrics and child health, Jimma University. Ethiop J Health Sci 2008; 18:47-52.

22. Khan A, Ayub M, Shah Z. An audit of the medical students' perceptions regarding objective structured clinical examination. Educ Res Int 2016; 2016:4806398. https://doi.org/10.1155/2016/ 4806398.

23. Massey D, Byrne J, Higgins N, Weeks B, Shuker MA, Coyne E, et al. Enhancing OSCE preparedness with video exemplars in undergraduate nursing students. A mixed method study. Nurse Educ Today 2017; 54:56-61. https://doi.org/10.1016/j.nedt.20 17.02.024.

24. Jay A. Students' perceptions of the OSCE: A valid assessment tool? Br J Midwifery 2007; 15:32-7. https://doi.org/10.12968/ bjom.2007.15.1.22677.

25. Bani-issa W, Al Tamimi M, Fakhry R, Al Tawil H. Experiences of nursing students and examiners with the objective structured clinical examination method in physical assessment education: A mixed methods study. Nurse Educ Pract 2019; 35:83-9. https://doi.org/10.1016/j.nepr.2019.01.006.

26. Aung KT, binti Zakaria AN. Nursing students' perceptions on objective structured clinical examination (OSCE). Perception 2016; 4:220-3. https://doi.org/10.4103/2321-7006.306243. 